\title{
Effects of Dezocine and Sufentanil on ThI/Th2 Balance in Breast Cancer Patients Undergoing Surgery
}

\author{
Xudong $\mathrm{Hu}^{\mathrm{l}, *}$ \\ Bing Luo ${ }^{2, *}$ \\ Qing $W^{2}$ \\ Qingbiao Chen ${ }^{2}$ \\ Penghui $\mathrm{Lu}^{2}$ \\ Jie Huang ${ }^{3}$ \\ Xiaoxia Liang' \\ Cheng Ling' \\ Yiqun $\mathrm{Li}^{2}$
}

'Department of Anesthesiology, The Second People's Hospital of Foshan, Foshan, Guangdong, 528000, People's Republic of China; ${ }^{2}$ Department of Surgery, The Second People's Hospital of Foshan, Foshan, Guangdong, 528000, People's Republic of China; ${ }^{3}$ Clinical Laboratory, The Second People's Hospital of Foshan, Foshan, Guangdong, 528000, People's Republic of China

*These authors contributed equally to this work
Background: It is very important for breast cancer patients undergoing surgery to choose an opioid that has little effect on the immune system. The aim of this study is to compare the effects of dezocine or sufentanil on postoperative pain and Th1/Th2 balance in patients undergoing breast cancer surgery.

Methods: Data from 92 breast cancer patients from January 2019 to July 2020 at Foshan Second People's Hospital (Guangdong, China) were analyzed. Sufentanil (SF) was used in group SF $(n=44)$ and dezocine (DE) in group DE $(n=48)$. The Visual Analog Scale (VAS) scores were assessed, and the percentages of Th1 cells and Th2 cells in peripheral blood were detected before anesthesia and at 2, 12, 24, and 48 hours after surgery.

Results: There was no significant difference in the VAS scores between the two groups at 2, 24, and 48 hours after surgery $(\mathrm{P}>0.05)$. The VAS scores at 12 hours after surgery in group DE were significantly lower than those in group SF with a statistically significant difference $(\mathrm{P}<$ 0.05). The percentage of Th1 cells in group DE at 2, 12, 24, and 48 hours after surgery was significantly lower than that in group SF $(\mathrm{P}<0.05)$. The percentage of Th2 cells in group DE at $2,12,24$, and 48 hours after surgery was significantly lower than that in group SF $(\mathrm{P}<0.05)$. The Th1/Th2 ratio at 2, 12, 24, and 48 hours after surgery was significantly higher in group DE than that in group SF $(\mathrm{P}<0.05)$.

Conclusion: Dezocine for anesthesia induction and postoperative analgesia can maintain the balance of Th1/Th2 more stable than, with the same analgesia efficacy as, sufentanil during the early postoperative period in breast cancer patients undergoing surgery.

Keywords: dezocine, sufentanil, VAS, Th1/Th2 balance, breast cancer

\section{Introduction}

Breast cancer is the most common malignant tumor in women, and its global morbidity has recently increased at a rate of over 2 million per year. ${ }^{1,2}$ Surgery is the main treatment for breast cancer, but postoperative recurrence and metastasis are still the leading causes of death in breast cancer patients, though neoadjuvant therapy improves the tumor-free survival and overall survival in patients with breast cancer. $^{2,3}$ The immunity of cancer patients, especially cellular immunity, plays a vital role in the body's antitumor defense mechanisms. ${ }^{4-6}$ The stress response caused by surgery and postoperative pain may induce the release of certain hormones and cytokines that are mediated by the sympathetic nervous system and the hypothalamic-pituitary-adrenal axis. ${ }^{4-6}$ which may cause immunosuppression in which the Th1/Th2 balance shifts toward the Th2 phenotype. ${ }^{7,8}$ Furthermore,
Correspondence: Yiqun $\mathrm{Li}$ Department of Surgery, The Second People's Hospital of Foshan, No. 78

Weiguo Road, Foshan, Guangdong,

528000, People's Republic of China

Tel +86 I390284562।

Fax +8675788032008

Email yiqunlide03@I63.com 
nociceptive stimuli such as pain are also involved in immune regulation through the signaling pathways in the central nervous system. Therefore, opioids should be used perioperatively in anesthesia and analgesia to reduce the stress response and alleviate pain, and, especially for cancer patients, to maintain normal immunity. ${ }^{4-7}$ But the wellknown side effects of opioids, suppression of the immune system has been increasingly reported, and the concern that their immunological effects during and after surgery may impact disease processes, especially cancer, has increased proportionally. ${ }^{4,5}$

$\mathrm{T}$ helper cell (Th cell) is the key regulator of host in anti-tumour immunity and its specialized subsets are generated following activation through lineage-specifying cytokines and transcriptional programs, such as T-bet and GATA3 $^{8,9}$ in which differentiation of Th1 cells is promoted by the cytokine IL-12, while IL-4 drives Th2 cell differentiation. These cytokines influence each other, in which the balance of Th1/Th2 was maintained stable and the body immunity is in normal. ${ }^{6,7} \mathrm{Th} 1$ cells and Th2 cells were first resigned by Mosmann in 1986, ${ }^{9}$ and other Th cells such as $\mathrm{T}$ regulatory cells (Treg), Th17 cells, $\mathrm{T}$ follicular helper (Tfh cells), Th9 cells and Th22 cell, with fewer expression, were described one after another after 30 years. ${ }^{10,11}$ However, the expression of Th1 cells and Th2 cells and the balance of Th1/Th2 play a very important role in antitumor immunity and are usually used as an indicator for the immunity status of cancer patients. ${ }^{7,8}$ Optimally, the Th1/Th2 balance would be Th1 predominant in the case of cancer. Th1 cells have been shown to have strong anticancer properties by increasing the activity of $\mathrm{NK}$ cells and CD8+ cells. In comparison, Th2 cells inhibit immune function and avoid autoimmune diseases caused by excessive immune function ${ }^{12}$. The balance of Th1/Th2 and must be maintained stable and predominantly shifted to Th1 and is an important indicator of cellular immune function in patients with breast cancer. ${ }^{9,13,14}$ Moreover, the perioperative changes of Th1 cells and T2 cells are associated with the size of tumors, pathological parameters, clinical stages and tumor-free survival outcomes, ${ }^{14}$ and the deviation of Th1/ Th2 balance to Th2 style was positively related to the metastasis and recurrence and the prognosis of breast cancer patients. ${ }^{9,14-16}$ Study also found that an increase in the Th1/Th2 ratio could suppress the growth and proliferation of breast cancer in rats and in mice. ${ }^{18,19}$

Opioids such as morphine, fentanyl, sufentanil and dezocine were usually used for anesthesia induction and postoperative analgesia in clinical practice. ${ }^{16,17,20}$ However, clinical studies on opioids usually involve with one opioid such as fentanyl or sufentanil for anesthesia induction and other opioids such as morphine or dezocine for postoperative analgesia ${ }^{16,17,20}$.

Morphine can inhibit Th cells from differentiating into Th1 cells, resulting in the reduction of the ratio of Th1/ Th2 through NF-kB, PI3K/AKT, T-bet and GATA3 and up-regulating IL-2 and IFN- $\gamma$ expression and downregulating IL-4 and IL-5 expression. ${ }^{21-24}$ Though Messmer et al found that morphine enhanced the $\mathrm{T}$ cell activation and increased IL-12 secretion, indicating positive effects on immune function. ${ }^{25}$ Most studies available on the immunological properties of opioids refer to morphine. Although morphine remains a standard opioid for analgesia in clinical practice and for study on the immune function, other semisynthetic and synthetic opioids such as sufentanil and dezocine are frequently used in the anesthesia and postoperative analgesia in cancer patients undergoing surgery. Although most data are derived from preclinical studies, it is emerging that different opioids have different effects on the body immune function. ${ }^{4}$

Sufentanil, a selective $\mu$ opioid-receptor agonist, can rapidly spread to various tissues and penetrate the bloodbrain barrier to reach an effective concentration to be of analgesic intensity, long duration, low toxicity, and wide safety range, as well as side effects similar to other opioids, including immune-suppression. ${ }^{26}$ It was also found that, with the same analgesic effect, sufentanil had a stronger effect than fentanyl on the increase of Treg cells in vitro. ${ }^{27}$ Moreover, sufentanil may decrease the $\mathrm{CD}^{+} /$ $\mathrm{CD}^{+}$ratio and increase the frequency of Treg cells. ${ }^{28,29}$ Treg cells in the breast cancer were positively associated with disease progression, and the $\mathrm{CD} 8+/$ Treg ratio was associated with lymph node metastasis and tumor staging. ${ }^{31}$ Treg cells are considered immuno-suppressive cells, similar to Th2 cells. ${ }^{31}$ Also, studies found that patients with breast cancer had the proportion of $\mathrm{CD}^{+}$ and $\mathrm{CD}^{+} \mathrm{T}$ cells in the sentinel lymph node reversed, meaning metastasis of breast cancer and significantly associated with both relapse-free survival and overall survival. ${ }^{30,31}$

Dezocine is widely used in perioperative anesthesia and postoperative analgesia in China due to its effective analgesic efficacy and fewer adverse events. ${ }^{16,17}$ Dezocine is a partial $\mu$ receptor agonist and partial $\kappa$ receptor agonist, which can inhibit the uptake of serotonin and epinephrine, similar to tramadol, and may have a similar 
protective effect on immunity. ${ }^{32,33}$ Studies have found that dezocine can up-regulate the level of IL-12 and downregulate the level of IL-10 in human umbilical cord blood dendritic cells, ${ }^{34}$ improve the proliferation and cytotoxicity of $\mathrm{CD}^{+}$cells, promote the maturation of BMDC, and inhibit tumor metastasis in rats. ${ }^{35,36}$

Wang et al found that the postoperative analgesic effect for breast cancer patients is slightly better with sufentanil than with dezocine. However, dezocine can reduce the inhibition of $\mathrm{NK}$ cell and $\mathrm{CD}^{+}$cell activity and maintain the balance of $\mathrm{CD}^{+} / \mathrm{CD}^{+}$, which is more conducive to the recovery of immune function. ${ }^{20}$ However, the effects of dezocine and sufentanil on Th cell differentiation remain unknown at present. This study aims to investigate the effects of dezocine and sufentanil on the Th1/Th2 balance in patients undergoing breast cancer surgery and provide a clinical basis for the selection of opioids with little negative impact on the immunity in breast cancer patients undergoing surgery.

\section{Materials and Methods Study Subjects}

Data from 92 patients with breast cancer at the Second People's Hospital of Foshan (Guangdong, China) from January 2019 to July 2020 were analyzed. Ethical approval was provided by the Ethics Committee of the hospital on November 1, 2018 (Approval document No: 2018-1105). Prior to the collection of the data, written informed consent was obtained from all participants. Patients with American Society of Anesthesiologist (ASA) status I to III, aged from 25 to 85 years, and scheduled for selective surgery were eligible. ${ }^{37}$ Exclusion criteria were refusal to participate in the study; allergy to the drugs used in the study; a history of autoimmune, endocrine, or metabolic disease; administration of opioids, steroids, or immunosuppressants; or cognitive impairment (unable to understand the VAS pain scale). All patients were treated with patient-controlled intravenous analgesia (PCIA). Modified radical mastectomy (MRM) or breast-conserving surgery (BCS) or simple mastectomy (SM) was performed on all patients with an axillary lymph node dissection or a sentinel lymph node biopsy, if necessary. Forty-four cases were treated with sufentanil as group SF and 48 cases were treated with dezocine as group DE. The general data of the two groups had no statistical differences $(\mathrm{P}>0.05)$ and were comparable.

\section{Anesthesia Method}

All patients fasted for 6-8 hours before surgery. Noninvasive blood pressure (NBP), electrocardiogram (ECG), heart rate (HR), pulse blood oxygen saturation $\left(\mathrm{SPO}_{2}\right)$, and Bispectral Index (BIS) were monitored with a vital sign monitor (PHILIPS MX50, Philips China Medical Devices Co. Ltd., China). An indwelling venous catheter was inserted into the elbow vein to establish venous access, and sodium lactate solution was infused at a rate of $6-8 \mathrm{~mL} / \mathrm{kg} / \mathrm{min}$. Before the induction of anesthesia, sufentanil $0.4 \mu \mathrm{g} / \mathrm{kg}$ (Yichang Humanwell Pharmaceutical Co. Ltd., China) and dezocine $0.2 \mathrm{mg} / \mathrm{kg}$ (Jiangsu Yangzijiang Pharmaceutical Co. Ltd., China) was injected intravenously into group SF and group DE, respectively. The anesthesia was then induced with propofol TCI set at $4 \mu \mathrm{g} / \mathrm{mL}$ of the plasma concentration. Muscle relaxation was facilitated by the administration of cisatracurium. The anesthesia was maintained with an inhalation concentration of $2-3 \%$ sevoflurane in $70 \%$ oxygen with a fresh gas flow of $2 \mathrm{~mL} / \mathrm{min}$ and balanced with propofol TCI set at a plasma concentration of 1.5-2 ug/ $\mathrm{mL}$. The BIS was kept between 40 and 60 by adjusting both the inhalation concentration of sevoflurane and the plasma concentration of propofol. An additional bolus of $5-10 \mu \mathrm{g}$ of sufentanil in group SF or 2.5-5.0 mg of dezocine in group DE was administered if significant tachycardia (above 20\% from baseline) or hypertension (above 20\% from baseline) occurred that was judged to be caused by a lack of analgesia. Mechanical ventilation was targeted to maintain an end-tidal $\mathrm{PCO}_{2}$ at $35-45$ $\mathrm{mmHg}$ during surgery. The patients were transferred to the post-anesthesia care unit (PACU) after the surgery was completed. Muscle relaxation was antagonized with neostigmine and atropine before the tracheal catheter was pulled out. Patients were observed in PACU and transferred back to the ward when the Edward score matched the discharge criterion.

\section{Postoperative Analgesia}

Patients in both groups received PCIA for 48 hours after surgery. A disposable, mechanical analgesia pump was used (Zhuhai Fornia Medical Equipment Co. Ltd., China). The pump was filled with dezocine $0.8 \mathrm{mg} / \mathrm{kg}$ or sufentanil $1.5 \mu \mathrm{g} / \mathrm{kg}$ diluted in $100 \mathrm{~mL}$ of normal saline for group DE and group SF, respectively. Dezocine $5 \mathrm{mg}$ in group DE or sufentanil $10 \mu \mathrm{g}$ in group SF was administered intravenously for pre-charge of the analgesia and citrate tropisetron $2 \mathrm{mg}$ was administered intravenously 
for the prevention of postoperative nausea and vomiting (PONV), $30 \mathrm{~min}$ before the operation concluded. The analgesia pump parameters were set to a background infusion of $2 \mathrm{~mL} / \mathrm{h}$, a PCIA dose of $1 \mathrm{~mL}$, and a locking time of $15 \mathrm{~min}$.

It was found that using different opioids in combination may have uncertain agonist/antagonist effects on the opioid receptor, resulting in uncertain pharmacological effects including analgesia, unwanted adverse effects and immune regulation. ${ }^{38-40}$ Therefore the results of such studies are not reflective of the pharmacological effects of a certain opioids in an accurate manner. A clinical study in which only one opioids involved in both anesthesia induction and postoperative analgesia should be made for a precise understanding of the pharmacodynamics of opioids.

We selected dezocine or sufentanil, as an opiate for anesthesia and analgesia options for breast cancer patients, respectively, with the regimen and the dosage used according to the references or guidelines and the Chinese expert consensus. ${ }^{41,42}$

\section{ThI Cells and Th2 Cells Measurement}

A $2 \mathrm{~mL}$ peripheral blood sample was collected from the elbow vein before surgery and 2, 12, 24, and 48 hours after surgery in an anticoagulant tube containing sodium heparin.

A $100 \mu$ ll blood sample and $1 \mu \mathrm{L}$ of mixed stimulants (ION/PMA/MON) (Hangzhou Lianke Biotech Co. Ltd., China) were mixed in a flow tube containing RPMI 1640 culture fluid (Gibco Biotechnology Co. Ltd., USA) $100 \mu \mathrm{L}$. The instructions were strictly followed when adding the dosage of all reagents. The flow tube with the specimen was placed in an incubator (Heraeus Scientific Co. Ltd., China) containing 5\% CO2 for 4 to 6 hours after blending, then the serum was taken out. Anti-CD3 antibody (PERCP Mouse Anti-Human CD3, 340456, BD Biotechnology Co. Ltd., USA) $20 \mathrm{ul}$ and anti-CD8 antibody (APC Mouse Anti-Human CD8, 347344, BD Biotechnology Co. Ltd., USA) $5 \mu \mathrm{L}$ were added to the flow tube and incubated for $15 \mathrm{~min}$ at room temperature in the dark. Lysing solution (BD Biotechnology Co. Ltd., USA) $2 \mathrm{~mL}$ diluted to $1 \times$ was added to the tube, which was similarly incubated for $10-15 \mathrm{~min}$. PBS $2 \mathrm{~mL}$ was added to the flow tube, which was centrifuged at $1500 \mathrm{rpm}$ for $5 \mathrm{~min}$. Next, permeabilization wash buffer (BioLegend, Biotechnology Co. Ltd., USA) $2 \mathrm{~mL}$ diluted to $1 \times$ was added to the tube, which was incubated in the dark at room temperature for $25 \mathrm{~min}$. The flow tube was centrifuged at $1500 \mathrm{rpm}$ for $5 \mathrm{~min}$ after PBS $2 \mathrm{~mL}$ was added. Next, anti-
IFN- $\gamma /$ IL-4 antibody (FAST IMMUNE Anti-IFN- $\gamma$ FITC/ IL-4 PE, 340584, BD Biotechnology Co. Ltd., USA) 20 ul was added to the flow tube, which was incubated in the dark at room temperature for $20 \mathrm{~min}$. The flow tube was centrifuged again at $1500 \mathrm{rpm}$ for $5 \mathrm{~min}$ after another addition of PBS $2 \mathrm{~mL}$, and the culture supernatant was discarded. At the end, PBS 400 ul was added to the flow tube, which was set to the flow cytometry (BD FACSCantoTM, USA) (SN: V33896001912) for Th cell detection. In this study, $\mathrm{CD} 3$ and $\mathrm{CD} 8$ gates were used to detect the $\mathrm{CD}^{+} \mathrm{CD}^{-}$cells represented as $\mathrm{CD}^{+} \mathrm{CD}^{+}$ cells, and the expression level of Th1/Th2 cells was analyzed according to the positive expression rates of IFN- $\gamma$ and IL- 4 in $\mathrm{CD}^{+} \mathrm{CD}^{-}$cells. Th1 cells were identified by $\mathrm{CD}^{+} \mathrm{CD} 8^{-} \mathrm{IFN}_{-} \gamma^{+}$and $\mathrm{Th} 2$ cells were identified by $\mathrm{CD}^{+} \mathrm{CD}^{-} \mathrm{IL}^{+} 4^{+}$(Figure 1). FACSDiva version 6.1.3 was used for the cell detection analysis.

\section{Observation Index}

General data: The ASA status, patient's age and body mass index (BMI), intravenous infusion volume and blood loss volume during surgery, the operation time, PCIA bolus times, clinicopathological stage of breast cancer, and surgical procedure were analyzed.

VAS scores: The VAS scores were assessed by a fixed anesthesiologist without prior knowledge of the patients' grouping at 2, 12, 24, and 48 hours after surgery. The VAS scores ranged from 0 to 10 , and the higher the score the higher the patient's pain index. The VAS is the most widely used tool for estimating both severity of pain and to judge the extent of pain relief. Healthcare workers ask the patient to select a point on a line drawn between the two ends to express how intense he/she perceives pain. In our study, VAS is a continuous scale comprised of a horizontal line, with $100 \mathrm{~mm}$ long, anchored by two verbal descriptors (ie, "no pain" and "worst imaginable pain". Patients are asked to rate "current" pain intensity or pain intensity "in the last 24 hour". The VAS is an easy-touse instrument that does not warrant using a sophisticated device. It is also highly sensitive in detecting treatment effects, and its results can be analysed by parametric tests. ${ }^{43}$ So, the VAS score was used in our study.

Th1 cells, Th2 cells, and Th1/Th2 ratio: The percentages of Th1 cells and Th2 cells in peripheral blood were detected before anesthesia and at 2, 12, 24, and 48 hours after surgery by flow cytometry in all patients. The Th1/ Th2 ratio was calculated with the percentages of Th1 cells and Th 2 cells, ie, Th1\% divided by Th2\%. 

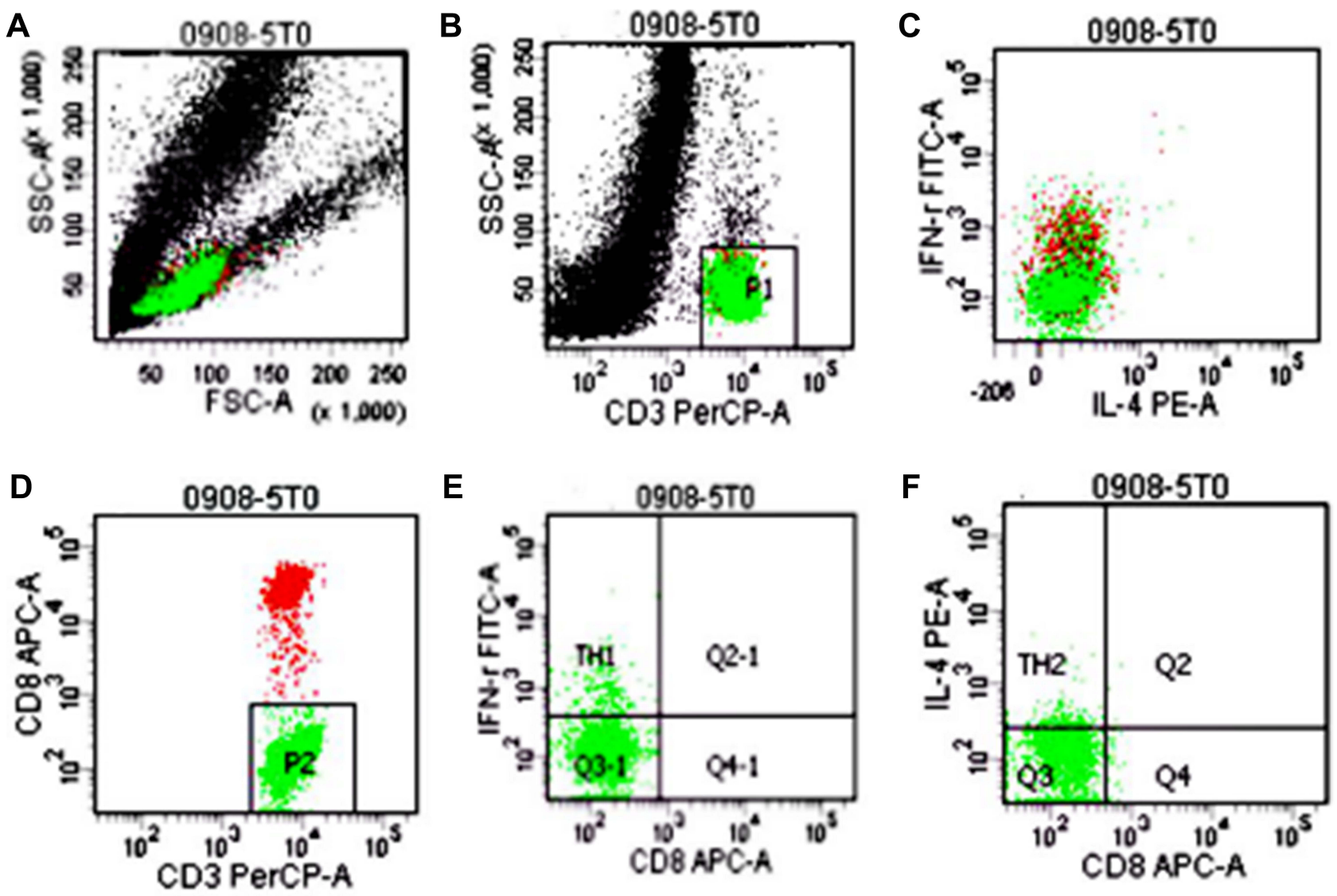

Figure I Detection chart of flow cytometry. $(\mathbf{A})$ is the lymphocyte portal and P0 is the lymphocytes in the whole blood sample; (B) is the $\mathrm{T}$ cell portal and PI is the CD $3^{+}$ $\mathrm{T}$ cells; $(\mathbf{C})$ is the $\mathrm{CD}^{+} \mathrm{T}$ cell portal and $\mathrm{P}$ is the mixture of the $\mathrm{CD}^{+} \mathrm{T}$ cells and the $\mathrm{CD} 8^{-} \mathrm{T}$ cells; (D) is the mixture of the $\mathrm{CD} 3^{+} \mathrm{T}$ cells and the $\mathrm{CD} 8^{-} \mathrm{T}$ cells portal and $\mathrm{P} 2$ is the $\mathrm{CD}^{+} \mathrm{CD}^{-} \mathrm{T}$ cells (T helper cells); (E) is the further analysis of the P2 portal and THI in the left upper quarter is the ThI cells; (F) is the further analysis of the P2 portal and $\mathrm{TH} 2$ in the left upper quarter is the Th2 cells.

Notes: In the figure, the black scattered points are lymphocytes; Green ones are CD4 + T cells; Red ones are CD8 + T cells.

\section{Statistical Analysis}

SPSS 23 (IBM SPSS, Armonk, NY, USA) was used for the data analysis. Test of normality using the Quantile-Quantile (Q-Q) plot on the continuous data was done. The normally distributed continuous data were described as mean \pm standard deviation $(\bar{x} \pm s)$ and tested using the $t$-test. Two-way ANOVA was used to compare VAS scores at different time points between groups. LSD test was used for the post-hoc analysis followed by the two-way ANOVA. Enumerated data were expressed as a percentage and differences between the two groups were analyzed by the Chi-square test. The grade data were analyzed using the Wilcoxon test. $\mathrm{P}<0.05$ was considered statistically significant.

\section{Results}

\section{General Data}

There was no statistical difference between the two groups in the general data of age, BMI, intra-operative intravenous infusion volume, intra-operative blood loss volume, operation time, PCIA bolus times, ASA status, clinicopathological stage of breast cancer, and surgical procedure $(\mathrm{P}=0.766$, $0.313,0.864,0.152,0.891,0.168,0.434,0.224,0.355, \mathrm{P}>$ $0.05)$, as shown in Table 1.

\section{VAS Scores}

Tables 2-4 show comparison of postoperative VAS scores in the two groups (Table 2), between time-points in Group SF (Table 3) and between time-points in Group DE (Table 4), and the indications are p-value and $t$ value in the column comparing between the readings in the two groups in individual; $F$ value and $p$-value in the column comparing between the readings of the two groups in the whole (Table 2); F value and $p$-value in the row comparing between the readings of the different time-points in the whole in each group; $p$-value in the column comparing between the readings of the different time-points of each other in each group (Table 3, Table 4).

There was no significant difference in the VAS score between the two groups at 2, 24, and 48 hours after surgery 
Table I Comparison of General Conditions of Patients in the Two Groups $(x \pm S)$

\begin{tabular}{|c|c|c|c|c|c|}
\hline \multicolumn{2}{|l|}{ Group } & Group SF $(n=44)$ & Group DE $(n=48)$ & Statistics Value & P-value \\
\hline \multicolumn{2}{|l|}{ Age (years) } & $57.02 \pm 13.39$ & $57.83 \pm|2.6|$ & $\mathrm{t}=0.30$ & 0.766 \\
\hline \multicolumn{2}{|l|}{ BMI $\left(\mathrm{kg} / \mathrm{m}^{2}\right)$} & $27.07 \pm 7.67$ & $25.73 \pm 4.29$ & $\mathrm{t}=1.017$ & 0.313 \\
\hline \multicolumn{2}{|c|}{ Intravenous infusion volume $(\mathrm{mL})$} & $700.34 \pm 120.63$ & $696.97 \pm 59.71$ & $\mathrm{t}=1.72$ & 0.864 \\
\hline \multicolumn{2}{|l|}{ Blood loss volume $(\mathrm{mL})$} & $76.97 \pm 8.72$ & $74.45 \pm 8.08$ & $\mathrm{t}=\mathrm{I} .44$ & 0.152 \\
\hline \multicolumn{2}{|l|}{ Operation time (min) } & $|28.9| \pm 28.00$ & $126.86 \pm 38.94$ & $\mathrm{t}=0.135$ & 0.891 \\
\hline \multicolumn{2}{|l|}{ PCA bolus times } & $4.27 \pm 0.0 .79$ & $4.62 \pm 1.50$ & $\mathrm{t}=1.36$ & 0.168 \\
\hline ASA status & I/II/III(case) & $14 / 24 / 6$ & $19 / 24 / 5$ & $Z=0.78$ & 0.434 \\
\hline Stage of breast cancer & $\mathrm{I} / \mathrm{II} \mathrm{A} / \mathrm{IIB} / \mathrm{III}$ (case) & $14 / 20 / 6 / 4$ & $12 / 22 / 12 / 2$ & $Z=1.22$ & 0.224 \\
\hline Type of operation & $\begin{array}{l}\text { SM(case) } \\
\text { BCS(case) } \\
\text { MRM(case) }\end{array}$ & $\begin{array}{l}8 \\
10 \\
26\end{array}$ & $\begin{array}{l}5 \\
8 \\
35\end{array}$ & $\chi^{2}=2.07$ & 0.355 \\
\hline
\end{tabular}

Table 2 Comparison of Postoperative VAS Scores in the Two Groups

\begin{tabular}{|c|c|c|c|c|}
\hline Time-Point & $\begin{array}{r}\text { Group SF } \\
(n=44)\end{array}$ & $\begin{array}{r}\text { Group DE } \\
\quad(n=48)\end{array}$ & t value & P-value \\
\hline TI; 2 h After surgery & $2.34 \pm 1.10$ & $2.27 \pm 1.25$ & 3.02 & 0.763 \\
\hline $\mathrm{T} 2 ; 12 \mathrm{~h}$ After surgery & $2.77 \pm 0.83$ & $2.31 \pm 0.85^{\wedge}$ & 2.62 & 0.010 \\
\hline T3; 24h After surgery & $2.52 \pm 0.82$ & $2.23 \pm 0.78$ & 1.76 & 0.082 \\
\hline T4; 48 h After surgery & $2.14 \pm 0.85$ & $1.85 \pm 0.71$ & 1.72 & 0.088 \\
\hline \multicolumn{3}{|c|}{ Two way ANOVA analysis in the two groups } & $\mathrm{F}=1.035$ & 0.3097 \\
\hline
\end{tabular}

Note: ${ }^{\Delta} \mathrm{P}<0.05$ compared with Group SF.

Table 3 Comparison of Postoperative VAS Scores Between Time-Points in Group SF

\begin{tabular}{|l|c|c|c|}
\hline Time-Point & Group SF (n=44) & LSD & P-value \\
\hline TI; 2 h After surgery & $2.34 \pm 1.10$ & $/$ & \\
T2; 12 h After surgery & $2.77 \pm 0.83$ & vs TI & 0.598 \\
T3; 24h After surgery & $2.52 \pm 0.82$ & vs TI, T2 & $0.451 ; 0.756$ \\
T4; 48 h After surgery & $2.14 \pm 0.85^{\text {d }}$ & vs TI, 2, T3 & $0.315 ; 0.068 ; 0.047$ \\
F value & 1.610 & $/$ & $/$ \\
P-value & 0.189 & $/$ & $/$ \\
\hline
\end{tabular}

Note: ${ }^{\mathrm{d}} \mathrm{P}<0.05$ compared with $24 \mathrm{~h}$ after surgery.

Table 4 Comparison of Postoperative VAS Scores Between Time-Point in Group DE

\begin{tabular}{|l|c|l|c|}
\hline Time-Point & Group DE $(\mathbf{n = 4 8 )}$ & LSD & P-value \\
\hline TI; 2 h After surgery & $2.27 \pm 1.25$ & $/$ & $/$ \\
T2; 12 h After surgery & $2.31 \pm 0.85$ & vs TI & 0.817 \\
T3; 24h After surgery & $2.23 \pm 0.78$ & vs TI, T2 & $0.817 ; 0.644$ \\
T4; 48 h After surgery & $1.85 \pm 0.71^{\text {bcd }}$ & vs TI, 2, T3 & $0.022 ; 0.012 ; 0.039$ \\
F value & 2.749 & $/$ & $/$ \\
P-value & 0.044 & $/$ & $/$ \\
\hline
\end{tabular}

Notes: ${ }^{\mathrm{b}} \mathrm{P}<0.05$ compared with $2 \mathrm{~h}$ after surgery; ${ }^{\mathrm{c}} \mathrm{P}<0.05$ compared with $12 \mathrm{~h}$ after surgery; ${ }^{\mathrm{d}} \mathrm{P}<0.05$ compared with $24 \mathrm{~h}$ after surgery.
$(\mathrm{P}=0.763,0.082,0.088, \mathrm{P}>0.05)$. The VAS scores at 12 hours after surgery in group DE were significantly lower than that in group SF, with a significantly statistical difference $(\mathrm{t}=2.62, \mathrm{P}=0.010, \mathrm{P}<0.05)$. But when the Two-way ANONA analysis is used between the two groups, $\mathrm{F}=$ $1.035, \mathrm{P}=0.3097, \mathrm{P}>0.05$. It is suggested that the VAS score during the analgesia period in Group DE and Group SF has no significantly statistical difference. The results indicate that dezocine has the same analgesic efficacy as sufentanil, as shown in Table 2, Figure 2.

There was no significant difference in the VAS scores at 2, 12, and 24 hours after surgery in group $\mathrm{SF}(\mathrm{P}=0.598$, $0.451,0.756, \mathrm{P}>0.05)$, and the VAS score at 48 hours after surgery was significantly lower than those at 12 hours after surgery $(\mathrm{P}=0.047, \mathrm{P}<0.05)$. Table 3, Figure 2 .

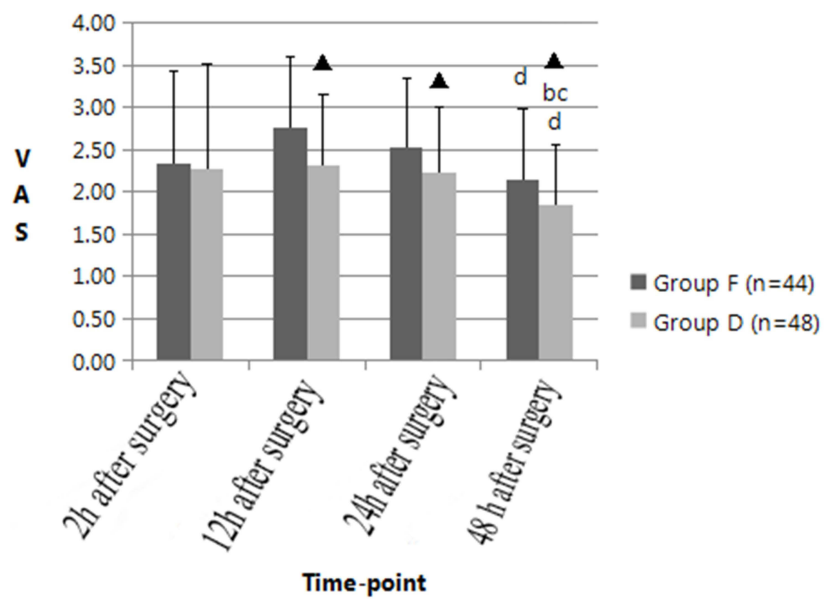

Figure 2 Comparison of VAS scores at 2, 12, and 24 hours after surgery between the two groups. ${ }^{b} \mathrm{P}<0.05$ compared with $2 \mathrm{~h}$ after surgery; ${ }^{\mathrm{C}} \mathrm{P}<0.05$ compared with $12 \mathrm{~h}$ after surgery; ${ }^{\mathrm{d}} \mathrm{P}<0.05$ compared with $24 \mathrm{~h}$ after surgery. ${ }^{\Delta} \mathrm{P}<0.05$ compared with Group SF. 
There was no significant difference in the VAS scores at 2,12 , and 24 hours after surgery in group DE ( $\mathrm{P}=$ $0.817,0.817,0.644, \mathrm{P}>0.05)$, and the VAS score at 48 hours after surgery was significantly lower than those at 2 , 12 , and 24 hours after surgery $(\mathrm{P}=0.022,0.012,0.039$, $\mathrm{P}<0.05)$. Table 4, Figure 2.

\section{ThI Cell Percentage Changes}

Research has shown that detecting the expression of internal factors $(\mathrm{FN}-\gamma / \mathrm{IL}-4)$ in Th cells $\left(\mathrm{CD} 4^{+}\right.$cells) by flow cytometry accurately reflects the Th1 and Th2 cell levels. The CD3 and CD4 gate was used for the detection of Th cells $\left(\mathrm{CD} 4^{+}\right.$cells), and Th1 and Th2 cells were determined by $\mathrm{CD} 4^{+} / \mathrm{IFN}-\gamma^{+}$and $\mathrm{CD} 4^{+} / \mathrm{IL}-4^{+}$, respectively. ${ }^{44,45}$ But during detection, the $\mathrm{CD}^{+}$molecule endocytosis occurs after PMA/Ionomycin stimulation, and then few $\mathrm{CD} 4^{+}$molecules can be detected. So, the $\mathrm{CD}^{+} / \mathrm{CD}^{-}$reverse gate can be used for Th cell $\left(\mathrm{CD}^{+}\right.$cells) detection because $\mathrm{CD}^{+}$cells consist mainly of $\mathrm{CD}^{+}$and $\mathrm{CD} 8^{+}$cells. This method suggested by Yang et al was used in our study. ${ }^{46,47}$

Tables 5-7 show comparison of Th1\% in the two groups (Table 5), between time-points in Group SF (Table 6) and between time-points in Group DE (Table 7), and the indications are $p$-value and t value in the column comparing between the readings in the two groups in individual; $p$-value and t value in the column comparing between the readings in the two groups in individual (Table 5); $\mathrm{F}$ value and $\mathrm{p}$-value in the row comparing between the readings of the different timepoints in the whole in each group; p-value in the column comparing between the readings of the different timepoints of each other in each group (Table 6, Table 7).

There was no significant difference in the percentage of Th1 cells between the two groups before surgery $(\mathrm{P}=0.487, \mathrm{P}>0.05)$, but the percentage of Th1 cells at $2,12,24$, and 48 hours after surgery in group DE was significantly higher than those in group SF, with

Table 5 Comparison of Thl\% in the Two Groups

\begin{tabular}{|l|c|c|c|c|}
\hline Time-Point & $\begin{array}{c}\text { Group SF } \\
(\mathbf{n = 4 4 )}\end{array}$ & $\begin{array}{c}\text { Group DE } \\
(\mathbf{n = 4 8 )}\end{array}$ & t value & P-value \\
\hline T0; Before Surgery & $16.12 \pm 4.50$ & $16.77 \pm 4.34$ & 0.7 & 0.487 \\
TI; 2 h After surgery & $12.34 \pm 3.29$ & $14.25 \pm 4.02^{\mathbf{\Delta}}$ & 2.48 & 0.015 \\
T2; 12 h After surgery & $11.51 \pm 3.87$ & $13.86 \pm 3.22^{\mathbf{\Delta}}$ & 3.18 & 0.002 \\
T3; 24h After surgery & $13.13 \pm 3.90$ & $14.95 \pm\left. 4.2\right|^{\mathbf{\Delta}}$ & 2.16 & 0.034 \\
T4; 48 h After surgery & $14.05 \pm 5.58$ & $16.47 \pm 2.88^{\mathbf{\Delta}}$ & 3.24 & 0.002 \\
\hline
\end{tabular}

Note: ${ }^{\mathbf{\Delta}} \mathrm{P}<0.05$ compared with Group SF.
Table 6 Comparison of Th I\% Between Time-Points in Group SF

\begin{tabular}{|l|c|l|c|}
\hline Time-Point & $\begin{array}{c}\text { Group SF } \\
(\mathbf{n = 4 4 )}\end{array}$ & \multicolumn{1}{|c|}{ LSD } & P-value \\
\hline T0; Before Surgery & $16.12 \pm 4.50$ & \multicolumn{1}{|c|}{$/$} & $/$ \\
TI; 2 h After surgery & $12.34 \pm 3.29^{\mathrm{a}}$ & vs T0, TI & 0.000 \\
T2; 12 h After surgery & $11.51 \pm 3.87^{\mathrm{a}}$ & vs T0, TI & $0.000 ; 0.321$ \\
T3; 24h After surgery & $13.13 \pm 3.90^{\text {ab }}$ & vs T0, TI, T2 & $0.000 ; 0.043$ \\
T4; 48 h After surgery & $14.05 \pm 5.58^{\text {abc }}$ & vs T0, TI, T2, T3 & $0.015 ; 0.043 ;$ \\
& & & $0.003 ; 0.271$ \\
F value & 8.902 & $/$ & $/$ \\
P-value & $<0.001$ & $/$ & $/$ \\
\hline
\end{tabular}

Notes: ${ }^{\mathrm{a}} \mathrm{P}<0.05$ compared with before surgery; ${ }^{\mathrm{b}} \mathrm{P}<0.05$ compared with $2 \mathrm{~h}$ after surgery; ${ }^{c} \mathrm{P}<0.05$ compared with $12 \mathrm{~h}$ after surgery.

statistically significant differences $(\mathrm{P}=0.015,0.002$, $0.034,0.002, \mathrm{P}<0.05)$, as shown in Table 5, Figure 3 $(0.000 ; 0.321,0.000 ; 0.043,0.015 ; 0.271)$.

The percentage of Th1 cells at 2, 12, and 24 hours after surgery in group SF was significantly lower than that before surgery, with statistically significant differences $(\mathrm{P}=0.000$, $0.000,0.000, \mathrm{P}<0.05)$. The percentage of Th1 cells at 24 hours after surgery was significantly higher than that at 2 hours after surgery, with a statistically significant difference $(\mathrm{P}=0.043, \mathrm{P}<0.05)$. The percentage of Th1 cells at 48 hours after surgery was significantly higher than those at 2 and 12 hours after surgery, with statistically significant differences $(\mathrm{P}=0.043 ; 0.003, \mathrm{P}<0.05)$. There was no significant difference in the percentage of Th1 cells before surgery and 48 hours after surgery $(\mathrm{P}=0.015, \mathrm{P}>0.05)$. These results indicate that the percentage of Th1 cells at 48 hours after surgery had not returned to the preoperative levels in group SF (14.05 \pm 5.58 , vs $16.12 \pm 4.50)$, as shown in Table 6, Figure 3.

The percentage of Th1 cells at 2, 12, 24, and 48 hours after surgery in group DE was significantly lower than that before surgery, with statistically significant differences $(\mathrm{P}=0.001,0.000,0.020, \mathrm{P}<0.05)$.

There was no significant difference in the percentage of Th1 cells between 2, 12, and 24 hours after surgery $(\mathrm{P}=0.607$, $0.365,0.165, \mathrm{P}>0.05$ ). The percentage of Th1 cells at 48 hours after surgery was significantly higher than that at 2, 12 hours after surgery, with statistically significant differences $(\mathrm{P}=$ $0.005,0.001, \mathrm{P}<0.05)$. There was no significant difference in the percentage of Th1 cells between before surgery and 48 hours after surgery $(16.47 \pm 2.88$ vs $16.77 \pm 4.34, \mathrm{P}=0.697>$ $0.05)$. These results indicate that the percentage of Th1 cells at 48 hours after surgery had returned to the preoperative levels in group DE, as shown in Table 7, Figure 3. 
Table 7 Comparison of ThI\% Between Time-Points in Group DE

\begin{tabular}{|l|c|c|c|}
\hline Time-Point & Group DE (n=48) & LSD & P-value \\
\hline T0 Before Surgery & $16.77 \pm 4.34$ & / & 0.001 \\
T1 2 h After surgery & $14.25 \pm 4.02^{\mathrm{a}}$ & vs T0, TI & $0.000 ; 0.607$ \\
T2 I2 h After surgery & $13.86 \pm 3.22^{\mathrm{a}}$ & vs T0, TI & $0.020 ; 0.365 ; 0.165$ \\
T3 24 h After surgery & $14.95 \pm 4.21^{\mathrm{a}}$ & vs T0, TI, T2 & $0.697 ; 0.005 ; 0.001 ; 0.051$ \\
T4 48 h After surgery & $16.47 \pm 2.88^{\mathrm{bc}}$ & vs T0, TI, T2, T3 & \\
F value & 5.711 & & $/$ \\
P-value & $<0.001$ & & \\
\hline
\end{tabular}

Notes: ${ }^{\text {a }} \mathrm{P}<0.05$ compared with before surgery; ${ }^{\mathrm{b}} \mathrm{P}<0.05$ compared with $2 \mathrm{~h}$ after surgery; ${ }^{\mathrm{c}} \mathrm{P}<0.05$ compared with $12 \mathrm{~h}$ after surgery.

\section{Th2 Cell Percentage Changes}

Tables $8-10$ show comparison of Th $2 \%$ in the two groups (Table 8), between time-points in Group SF (Table 9) between time-points in Group DE (Table 10) and the indications are $p$-value and $t$ value in the column comparing between the readings in the two groups of individuals (Table 8); $\mathrm{F}$ value and $\mathrm{p}$-value in the row comparing between the readings of the different time-points in the whole of each group; p-value in the column comparing between the readings of the different time-points of each other in each group (Table 9, Table 10).

There was no significant difference in the percentage of Th2 cells between the two groups before surgery ( $\mathrm{P}=$ $0.297, \mathrm{P}>0.05$ ), and the percentage of Th2 cells at 2 , 12,24 , and 48 hours after surgery in group DE was significantly lower than those in group SF, with statistically significant differences $(\mathrm{P}=0.024 .0 .0001,0.023$, $0.013, \mathrm{P}<0.05)$, as shown in Table 8 , Figure 4 .

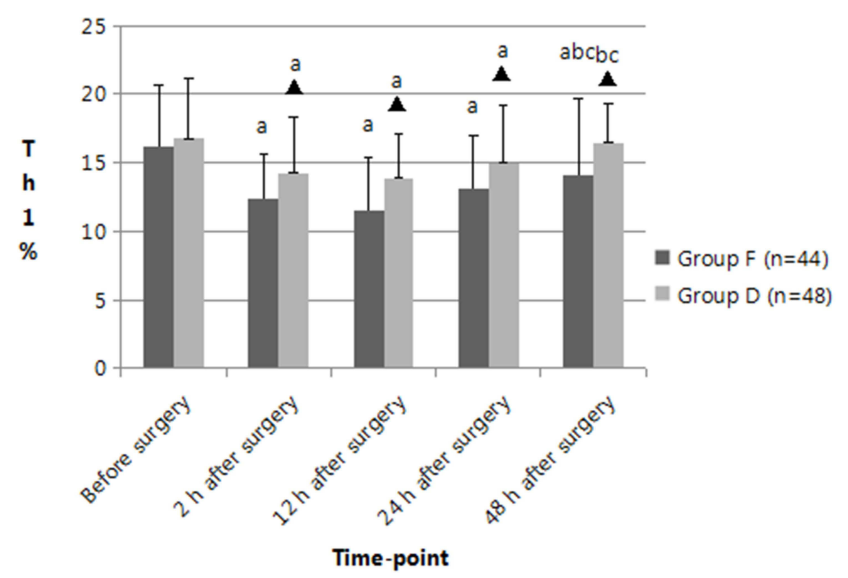

Figure 3 Comparison of the percentage of Thl cells before and after surgery between the two groups. ${ }^{a} \mathrm{P}<0.05$ compared with before surgery, ${ }^{\mathrm{b}} \mathrm{P}<0.05 \mathrm{com}-$ pared with $2 \mathrm{~h}$ after surgery; ${ }^{\mathrm{C}} \mathrm{P}<0.05$ compared with $12 \mathrm{~h}$ after surgery. ${ }^{\boldsymbol{\Delta}} \mathrm{P}<0.05$ compared with Group SF.
The percentage of Th2 cells at 2, 12, and 24 hours after surgery in group SF was significantly higher than that before surgery, with statistically significant differences (All $\mathrm{P}=0.000, \mathrm{P}<0.05$ ). The percentage of Th2 cells at 48 hours after surgery was significantly lower than those at 2 and 12 hours after surgery, with a statistically significant difference $(\mathrm{P}=0.000,0.002, \mathrm{P}<0.05)$. There was no significant difference in the percentage of Th2 cells between 2, 12, 24 hours after surgery $(\mathrm{P}=0.524,0.051$, $0.186, \mathrm{P}>0.05)$. The percentage of Th2 cells at 48 hours after surgery in group SF was significantly higher than that before surgery, with a statistically significant difference $(4.11 \pm 1.06$ vs $3.25 \pm 1.12, \mathrm{P}=0.064, \mathrm{P}>0.05$,). These results indicate that the percentage of Th2 cells at 48 hours after surgery had not returned to the preoperative levels in group SF, as shown in Table 9, Figure 4.

The percentage of Th2 cells at 2, 12, 24, and 48 hours after surgery in group DE was significantly higher than those before surgery, with statistically significant differences $(\mathrm{P}=0.000,0.006,0.015, \mathrm{P}<0.05)$. The percentage of Th2 cells at 48 hours after surgery was significantly higher than that at 2, 12 and 24 hours after surgery, with statistically significant differences $(\mathrm{P}=0.000,0.015,0.031, \mathrm{P}<0.05)$. The percentage of Th2 cells at 24 hours after surgery was significantly higher than that at 2 hours after surgery, with a statistically significant difference $(\mathrm{P}=0.024, \mathrm{P}<0.05)$. There was no significant difference in the percentage of $\mathrm{Th} 2$ cells before surgery and 48 hours after surgery $(3.56 \pm 0.97 \mathrm{vs}$ $3.51 \pm 1.20, \mathrm{P}=0.773, \mathrm{P}>0.05)$. These results indicate that the percentage of Th2 cells at 48 hours after surgery had returned to the preoperative levels in group $\mathrm{DE}$, as shown in Table 10, Figure 4.

\section{Th I/Th2 Ratio Changes}

Tables 11-13 show comparison of Th1/Th2 between the two groups (Table 11), between time-points in Group SF 
Table 8 Comparison of Th2\% in the Two Groups

\begin{tabular}{|l|c|c|c|c|}
\hline Time-Point & Group SF $(\mathbf{n = 4 4 )}$ & Group DE $(\mathbf{n = 4 8})$ & t value & P-value \\
\hline T0; Before Surgery & $3.25 \pm .1 .12$ & $3.5 I \pm 1.20$ & 1.05 & 0.297 \\
TI; 2 h After surgery & $5.00 \pm 1.54$ & $4.48 \pm 1.02^{\mathbf{\Delta}}$ & 2.3 & 0.024 \\
T2; 12 h After surgery & $4.86 \pm 0.97$ & $4.08 \pm 0.88^{\mathbf{\Delta}}$ & 4.04 & $0.000 \mathrm{I}$ \\
T3; 24h After surgery & $4.54 \pm 1.20$ & $4.01 \pm 0.98^{\mathbf{\Delta}}$ & 2.31 & 0.023 \\
T4; 48 h After surgery & $4.11 \pm 1.06$ & $3.56 \pm 0.97^{\mathbf{\Delta}}$ & 2.55 & 0.013 \\
P-value & $<0.0001$ & $<0.0001$ & & \\
\hline
\end{tabular}

Note: ${ }^{\Delta} \mathrm{P}<0.05$ compared with Group SF.

Table 9 Comparison of Th2\% Between Time-Points in Group SF

\begin{tabular}{|c|c|c|c|}
\hline Time-Point & Group SF $(n=44)$ & LSD & P-value \\
\hline T0; Before Surgery & $3.25 \pm .1 .12$ & I & \\
\hline TI; 2 h After surgery & $5.00 \pm 1.54^{\mathrm{a}}$ & vs T0, TI & 0.000 \\
\hline T2; 12 h After surgery & $4.86 \pm 0.97^{\mathrm{a}}$ & vs TO, TI & $0.000 ; 0.524$ \\
\hline T3; 24h After surgery & $4.54 \pm 1.20^{\mathrm{a}}$ & vs T0, TI, T2 & $0.000 ; 0.051 ; 0.186$ \\
\hline T4; 48 h After surgery & $4.11 \pm 1.06^{\mathrm{abc}}$ & vs T0, TI, T2, T3 & $0.000 ; 0.000 ; 0.002 ; 0.064$ \\
\hline$F$ value & 17.99 & I & \\
\hline P-value & $<0.0001$ & l & \\
\hline
\end{tabular}

Notes: ${ }^{\mathrm{a}} \mathrm{P}<0.05$ compared with before surgery; ${ }^{\mathrm{b}} \mathrm{P}<0.05$ compared with $2 \mathrm{~h}$ after surgery; ${ }^{\mathrm{C}} \mathrm{P}<0.05$ compared with $12 \mathrm{~h}$ after surgery.

Table 10 Comparison of Th2\% Between Time-Points in Group DE

\begin{tabular}{|c|c|c|c|}
\hline Time-Point & Group DE $(n=48)$ & LSD & P-value \\
\hline T0; Before Surgery & $3.51 \pm 1.20$ & l & \\
\hline TI; 2 h After surgery & $4.48 \pm 1.02^{\mathrm{a}}$ & vs T0, TI & 0.000 \\
\hline T2; 12 h After surgery & $4.08 \pm 0.88_{\mathrm{a}}$ & vs T0, TI & $0.006 ; 0.050$ \\
\hline T3; 24h After surgery & $4.01 \pm 0.98^{\mathrm{ab}}$ & vs T0, TI, T2 & $0.015 ; 0024 ; 0.77$ I \\
\hline T4; 48 h After surgery & $3.56 \pm 0.97^{\mathrm{bcd}}$ & vs T0, TI, T2, T3 & $0.773 ; 0.000 ; 0.015 ; 0.03 ।$ \\
\hline $\mathrm{F}$ value & 7.551 & I & \\
\hline P-value & $<0.0001$ & l & \\
\hline
\end{tabular}

Notes: ${ }^{\mathrm{a}} \mathrm{P}<0.05$ compared with before surgery; ${ }^{\mathrm{b}} \mathrm{P}<0.05$ compared with $2 \mathrm{~h}$ after surgery; ${ }^{\mathrm{C}} \mathrm{P}<0.05$ compared with $12 \mathrm{~h}$ after surgery; ${ }^{\mathrm{d}} \mathrm{P}<0.05$ compared with $24 \mathrm{~h}$ after surgery.

(Table 12) between time-points in Group DE (Table 13) and the indications are $\mathrm{p}$-value and $\mathrm{t}$ value in the column comparing between the readings of the two groups of individuals (Table 11), and $\mathrm{F}$ value and p-value in the row comparing between the readings of the different timepoints in the whole in each group; p-value in the column comparing between the readings of the different timepoints of each other in each group Table 12, Table 13).

There was no significant difference in the Th1/Th2 ratio before surgery between the two groups $(\mathrm{P}=0.078$, $\mathrm{P}>0.05)$, but the Th1/Th2 ratio at 2, 12, 24, and 48 hours after surgery in group DE was significantly higher than that in group SF, with statistically significant differences
$(\mathrm{P}=0.000,0.000,0.001, \mathrm{P}<0.05)$, as shown in Table 11, Figure 5.

The Th1/Th2 ratio at 2,12 , and 24 hours after surgery in group SF was significantly lower than that before surgery, with statistically significant differences (All $\mathrm{P}=$ $0.000, \mathrm{P}<0.05)$. The Th1/Th2 ratio at 48 hours after surgery was significantly lower than that at 2 and 12 hours after surgery, with statistically significant differences $(\mathrm{P}=0.000,0.012, \mathrm{P}<0.05)$. There was no significant difference in the $\mathrm{Th} 1 / \mathrm{Th} 2$ ratio between at 24 and 48 hours $(\mathrm{P}=0082, \mathrm{P}>0.05)$. The Th1/Th2 ratio at 48 hours after surgery was significantly lower than that before surgery, with a statistically significant difference (3.67 


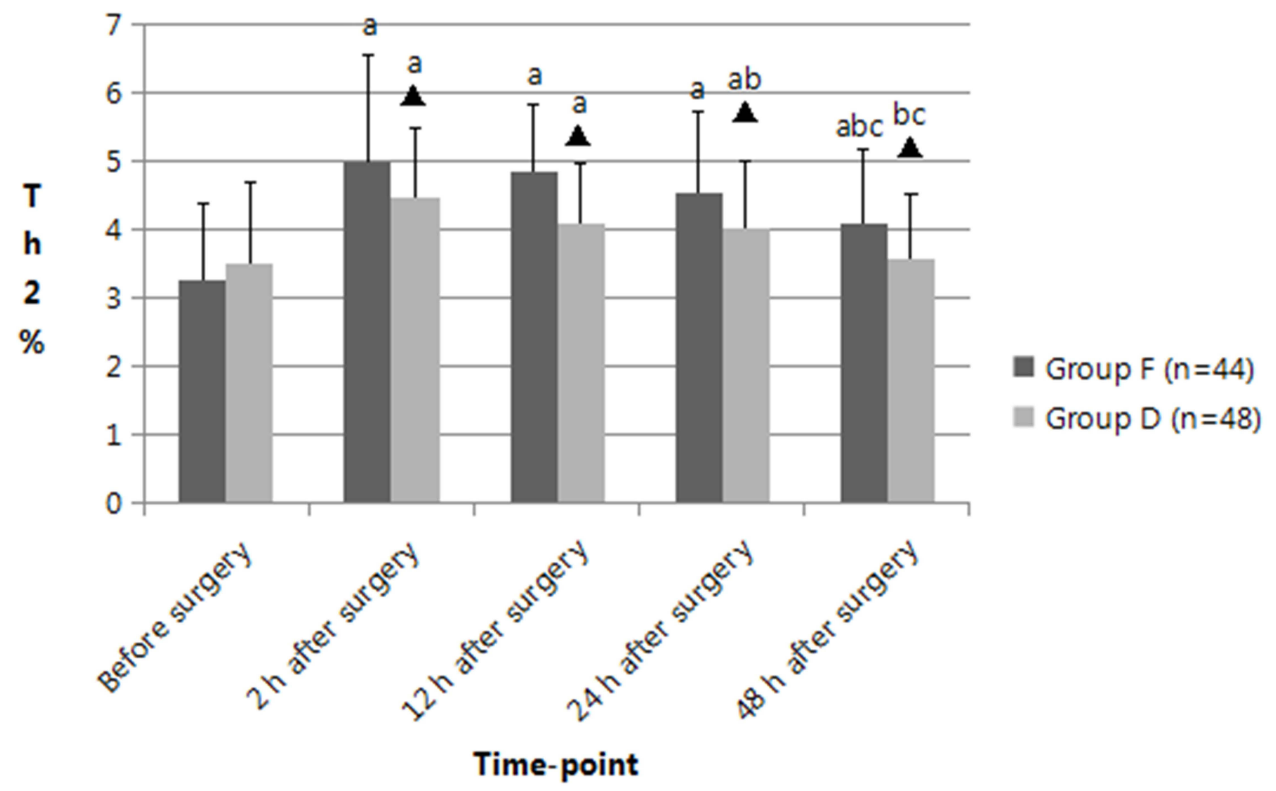

Figure 4 Comparison of the percentage of Th2 cells before and after surgery between the two groups. ${ }^{a} \mathrm{P}<0.05$ compared with before surgery, ${ }^{\mathrm{b}} \mathrm{P}<0.05$ compared with 2 $\mathrm{h}$ after surgery; ${ }^{\mathrm{C}} \mathrm{P}<0.05$ compared with $12 \mathrm{~h}$ after surgery. ${ }^{\mathbf{A}} \mathrm{P}<0.05$ compared with Group SF.

\pm 1.15 vs $4.07 \pm 0.96, \mathrm{P}=0.009, \mathrm{P}<0.05)$. These results indicate that the $\mathrm{Th} 1 / \mathrm{Th} 2$ ratio at 48 hours after surgery had returned to the preoperative levels in group SF but is still low, as shown in Table 12, Figure 5.

The Th1/Th2 ratio at 2 and 12 hours after surgery in group DE was significantly lower than that before surgery, with statistically significant differences $(\mathrm{P}=0.279,0.164$, $\mathrm{P}<0.05)$. The Th1/Th2 ratio at 24 and 48 hours after surgery was significantly lower than that at 2 hours after surgery, with statistically significant differences $(\mathrm{P}=$ $0.014,0.001, \mathrm{P}<0.05)$. The Th1/Th2 ratio at 48 hours after surgery was significantly lower than that at 12 hours after surgery, with a statistically significant difference $(\mathrm{P}=$ $0.032, \mathrm{P}<0.05)$. There was no significant difference in the Th1/Th2 ratio before surgery and 24 and 48 hours after surgery $(\mathrm{P}=0.264,0.714,0.447, \mathrm{P}>0.05)$. These results indicate that $\mathrm{Th} 1 / \mathrm{Th} 2$ ratio at 24 and 48 hours after surgery had returned to the preoperative levels in group DE, as shown in Table 13, Figure 5.

\section{Discussion}

There is reasonable evidence that opioids themselves can inhibit the immune function, mediating the balance of Th1/Th2 by activating the opioid receptors and beyond them. ${ }^{4-48}$ Research has shown that morphine can facilitate the differentiation of Th cells into Th2 cells and decrease the Th1/Th2 ratio. This effect can be reversed by naloxone $e^{21,25}$ and can be concealed in rats with the $\mu$ receptor gene being knocked out. ${ }^{21,22,48}$ These results indicate that the $\mu$ opioid receptor may, in part, mediate immunosuppression, by binding to $\mu$ opioid receptors expressed by T cells. ${ }^{4,10,49}$ Another study found that the treatment of human $\mathrm{T}$ lymphocytes with opioids resulted in a strong induction or reduction of the cytokine IL- $4{ }^{48}$ which is mainly involved in Th cell differentiation. ${ }^{47,48}$ Opioids also affect the immune system through other nonopioid receptor mechanisms, such as the sympathetic nervous system, the central nervous system, and the hypothalamic-pituitary-adrenal axis. ${ }^{5,50-52}$ Furthermore, the effect of tramadol on NK cell cytotoxicity following surgery might be the stimulation of NK activity, due to 5-HT reuptake and it can be inhibited by the 5-HT receptor antagonist metergoline. ${ }^{10,53}$ These results indicate that the 5-HT receptors also involve the immune regulation.

In our study, the decreased expression of Th1 cells and increased expression of Th2 cells resulted in a significantly decreased Th1/Th2 ratio after surgery at 2, 12 and 24 hours in both groups, indicating that Th cells can differentiate to Th2 cells under the influence of surgical stress and postoperative pain. These results are confirmed by previous studies. ${ }^{6-9}$ Our study also found that the percentages of Th1 and Th2 and the Th1/Th2 ratio were all restored to the preoperative levels at 48 hours after surgery in patients treated with dezocine, but in the patients treated with sufentanil, there was some in difference. Although there was no significant difference in the ratio of Th1/Th2 
Table I I Comparison of ThI/Th2 in the Two Groups

\begin{tabular}{|l|c|c|c|c|}
\hline Time-Point & $(\mathbf{n = 4 4 )}$ & $\mathbf{( n = 4 8 )}$ & t value & P-value \\
\hline T0; Before Surgery & $4.07 \pm 0.96$ & $4.14 \pm 1.13$ & 0.36 & 0.078 \\
TI; 2 h After surgery & $2.76 \pm 0.69$ & $3.45 \pm 0.79 \mathbf{\Delta}$ & 0 \\
T2;12 hAfter surgery & $3.01 \pm 0.79$ & $3.66 \pm 0.67^{\mathbf{\Delta}}$ & 4.45 & 0 \\
T3;24h After surgery & $3.18 \pm 0.81$ & $3.93 \pm .0 .97^{\mathbf{4}}$ & 3.42 & 0.001 \\
T4;48 hAfter surgery & $3.67 \pm 1.15$ & $4.07 \pm 1.09 \mathbf{\Delta}$ & 2.37 & 0.02 \\
\hline
\end{tabular}

Note: ${ }^{\wedge} \mathrm{P}<0.05$ compared with Group SF.

Table 12 Comparison of Th1/Th2 Between Time-Points in Group SF

\begin{tabular}{|l|c|l|c|}
\hline Time-Point & Group SF $(\mathbf{n = 4 4 )}$ & \multicolumn{1}{|c|}{ LSD } & \multicolumn{1}{c|}{$/$} \\
\hline T0; Before Surgery & $4.07 \pm 0.96$ & & 0.000 \\
TI; 2 h After surgery & $2.76 \pm 0.69^{\mathrm{a}}$ & vs T0, TI & $0000 ; 0.203$ \\
T2;12 hAfter surgery & $3.01 \pm 0.79^{\mathrm{a}}$ & vs T0, TI & $0.000 ; 0.041 ; 0.434$ \\
T3;24h After surgery & $3.18 \pm 0.8 \mathrm{I}^{\mathrm{ab}}$ & vs T0, TI, T2 & $0.009 ; 0.000 ; 0.012 ; 0.082$ \\
T4;48 hAfter surgery & $3.67 \pm 1.15^{\mathrm{abc}}$ & vs T0, TI, T2, T3 & $/$ \\
F value & 12.478 & & $/$ \\
P-value & $<0.00 \mathrm{I}$ & & $/$ \\
\hline
\end{tabular}

Notes: ${ }^{\mathrm{a}} \mathrm{P}<0.05$ compared with before surgery; ${ }^{\mathrm{b}} \mathrm{P}<0.05$ compared with $2 \mathrm{~h}$ after surgery; ${ }^{\mathrm{c}} \mathrm{P}<0.05$ compared with $12 \mathrm{~h}$ after surgery.

Table 13 Comparison of Th1/Th2 Between Time-Points in Group DE

\begin{tabular}{|l|c|l|c|}
\hline Time-Point & Group DE (n=48) & LSD & P-value \\
\hline T0; Before Surgery & $4.14 \pm 1.13$ & $/$ & \multicolumn{1}{|c|}{$/$} \\
TI; 2 h After surgery & $3.45 \pm 0.79^{\mathrm{a}}$ & vs T0, TI & 0.000 \\
T2;12 hAfter surgery & $3.66 \pm 0.67^{\mathrm{a}}$ & vs T0, TI & $0.012 ; 0.279$ \\
T3;24h After surgery & $3.93 \pm .0 .97^{\mathrm{b}}$ & vs T0, TI, T2 & $0.014 ; 0.164$ \\
T4;48 hAfter surgery & $4.07 \pm 1.09^{\mathrm{bc}}$ & vs T0, TI, T2, T3 & $/$ \\
F value & 4.586 & $/$ & $/$ \\
P-value & 0.01 & $/$ & $/ .001 ; 0.032 ; 0.447$ \\
\hline
\end{tabular}

Notes: ${ }^{\mathrm{a}} \mathrm{P}<0.05$ compared with before surgery; ${ }^{\mathrm{b}} \mathrm{P}<0.05$ compared with $2 \mathrm{~h}$ after surgery; ${ }^{\mathrm{c}} \mathrm{P}<0.05$ compared with $12 \mathrm{~h}$ after surgery.

between 48 hours after surgery and before surgery $(\mathrm{P}=0.82)$, the ratio of Th1/Th2 at 48 hours after surgery was still lower than that before surgery $(3.67 \pm 1.15$ vs $4.07 \pm 0.96)$.

Furthermore, the percentage of Th1 cells at 2, 12, 24, and 48 hours after surgery in patients treated with dezocine were significantly higher than those with sufentanil accompanied with the percentage of Th2 cells in reverse, resulting in higher Th1/Th2 ratio in the dezocine group at 2, 12, 24, and 48 hours after surgery than those with sufentanil. These results suggest that dezocine can inhibit the shift of the Th1/ Th2 balance to Th2 phenotype in the early postoperative period, whereas sufentanil has the weaker effect, and this immune protective effect may be beneficial to the recovery of cancer patients after surgery. These results can be explained as follows: First, as described above, opioid immunomodulatory effects are mediated, in part, by $\mu$ opioid receptors. ${ }^{4-}$ ${ }^{6,48}$ Sufentanil, similar to morphine, is a $\mu$ receptor agonist, can suppress the expression of s, IL-2, IFN- $\gamma$, and IL-12. The down-regulation of these cytokines inhibits Th cell differentiation in Th1 cells. ${ }^{48,49}$ However, dezocine, a partial $\kappa$ agonist, can prompt Th cell differentiation to Th1 cells by increasing the level of IL-12, decreasing the level of IL-10, and improving the activity of $\mathrm{CD}^{+}{ }^{+}$cells. ${ }^{34,35} \mathrm{IL}-12$ is a key cytokine in mediating cellular immunity, especially in inducing Th1 differentiation both in vivo and in vitro. ${ }^{25,27}$ In contrast to IL-12, IL-10 is a suppressive factor acting on antigen-presenting cells to inhibit cytokine secretion by Th1 cells. ${ }^{48,55}$ Second, studies have shown that tramadol, as a weak agonist of $\mu$ receptors, can reduce the differentiation 


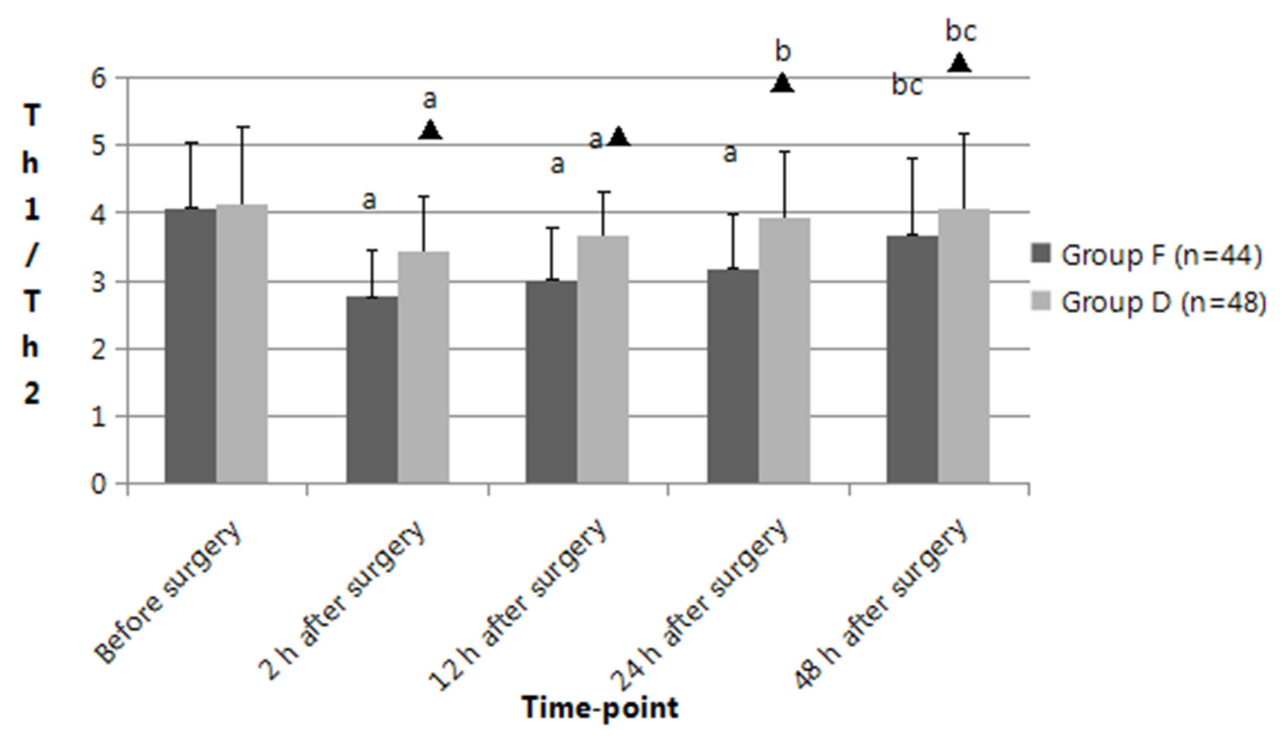

Figure 5 Comparison of the Th1/Th2 ratio before and after surgery between the two groups. ${ }^{\text {a }}<0.05$ compared with before surgery, ${ }^{b} \mathrm{P}<0.05$ compared with 2 h after surgery, ${ }^{\mathrm{C}} \mathrm{P}<0.05$ compared with $12 \mathrm{~h}$ after surgery. ${ }^{\boldsymbol{\Lambda}} \mathrm{P}<0.05$ compared with Group SF.

of Th cells into Th2 types. ${ }^{52-54}$ Dezocine, with similar pharmacological characteristics to tramadol, such as partial activation on $\mu$ receptors and inhibiting noradrenaline and serotonin reuptake ${ }^{17,32,33}$ may have an immune-stimulating effect. Previous studies have confirmed that serotonin (5-HT) may mediate the Th1 transition. ${ }^{56}$ Finally, we found that the analgesic efficacy of dezocine is the same as that of sufentanil in the whole but is better at 12 hours after surgery, and the decrease in pain may be beneficial to the immunity. ${ }^{53,57}$ All these mechanisms resulted in a slight decrease in the percentage of Th1 and the Th1/Th2 ratio in the early postoperative period and fast recovery in breast cancer patients undergoing surgery.

There are some limitations to this study. First, the study is retrospective and the results need to be confirmed by a randomized controlled blind study. Second, the changes in Th cells were only observed for 48 hours after surgery and the long-term immune response after surgery was not involved in this study. Finally, this study did not involve clinical outcomes such as postoperative recurrence and survival.

\section{Conclusion}

In conclusion, dezocine or sufentanil, used for anesthesia induction and postoperative analgesia, can achieve the same analgesic efficacy and dezocine can maintain the balance of Th1/Th2 more stable than sufentanil during the early postoperative periods and protect the body's antitumor immunity in breast cancer patients undergoing surgery.

\section{Ethics Approval}

This study was conducted in accordance with the declaration of Helsinki. This study was conducted with approval from the Ethics Committee of The Foshan Hospital of Southern Medical University on November 5 with the approval document No: 2018 (2018-1105).

\section{Consent}

A written informed consent was obtained from all participants. Consent for publication was obtained from every individual whose data are included in this manuscript.

\section{Funding}

This work was supported by the Fund of Science and Technology Project of Guangdong Province of China (No. 2012A030400042).

\section{Disclosure}

The authors report no conflicts of interest in this work.

\section{References}

1. Brentnall AR, Cuzick J, Buist DSM, et al. Long-term accuracy of breast cancer risk assessment combining classic risk factors and breast density. JAMA Oncol. 2018;4(9):e180174. doi:10.1001/ jamaoncol.2018.0174

2. Bray F, Ferlay J, Soerjomataram I, et al. Global cancer statistics 2018: GLOBOCAN estimates of incidence and mortality worldwide for 36 cancers in 185 countries. CA Cancer J Clin. 2018;68(6):394-424. doi: $10.3322 /$ caac. 21492 
3. Wang H, Mao X. Evaluation of the efficacy of neoadjuvant chemotherapy for breast cancer. Drug Des Devel Ther. 2020;14:2423-2433. doi:10.2147/DDDT.S253961

4. Franchi S, Moschetti G, Amodeo G, et al. Do all opioid drugs share the same immunomodulatory properties? A review from animal and human studies. Front Immunol. 2019;10:2914. doi:10.3389/ fimmu.2019.02914

5. Scarborough BM, Smith CB. Optimal pain management for patients with cancer in the modern era. CA Cancer J Clin. 2018;68 (3):182-196. doi:10.3322/caac. 21453

6. Zhou D, Gu FM, Gao Q, et al. Effects of anesthetic methods on preserving anti-tumor T-helper polarization following hepatectomy. World J Gastroenterol. 2012;18(24):3089-3098. doi:10.3748/wjg. v18.i24.3089

7. Wada H, Seki S, Takahashi T, et al. Combined spinal and general anesthesia attenuates liver metastasis by preserving TH1/TH2 cytokine balance. Anesthesiology. 2007;106(3):499-506. doi:10.1097/ 00000542-200703000-00014

8. Kaur RP, Vasudeva K, Singla $\mathrm{H}$, et al. Analysis of pro- and anti-inflammatory cytokine gene variants and serum cytokine levels as prognostic markers in breast cancer. J Cell Physiol. 2018;233 (12):9716-9723. doi:10.1002/jcp.26901

9. Mosmann TR, Cherwinski H, Bond MW, et al. Two types of murine helper T cell clone. I. Definition according to profiles of lymphokine activities and secreted proteins. 1986. J Immunol. 2005;175(1):5-14.

10. Harrington LE, Hatton RD, Mangan PR, et al. Interleukin 17-producing CD4+ effector T cells develop via a lineage distinct from the $\mathrm{T}$ helper type 1 and 2 lineages. Nat Immunol. 2005;6 (11):1123-1132. doi:10.1038/ni1254

11. Saravia J, Chapman NM, Chi H. Helper T cell differentiation. Cell Mol Immunol. 2019;16(7):634-643. doi:10.1038/s41423-019-0220-6

12. Mahlangu T, Dludla PV, Nyambuya TM, et al. A systematic review on the functional role of Th1/Th2 cytokines in type 2 diabetes and related metabolic complications. Cytokine. 2020;126:154892. doi:10.1016/j.cyto.2019.154892

13. Kennedy R, Celis E. Multiple roles for CD4+ T cells in anti-tumor immune responses. Immunol Rev. 2008;222:129-144. doi:10.1111/ j.1600-065X.2008.00616.x

14. Fu G, Miao L, Wang M, et al. The postoperative immunosuppressive phenotypes of peripheral $\mathrm{T}$ helper cells are associated with poor prognosis of breast cancer patients. Immunol Invest. 2017;46 (7):647-662. doi:10.1080/08820139.2017.1360337

15. Moyano J, Aguirre L. Opioids in the immune system: from experimental studies to clinical practice. Rev Assoc Med Bras (1992). 2019;65(2):262-269. doi:10.1590/1806-9282.65.2.262

16. Wang L, Liu X, Wang J, et al. Comparison of the efficacy and safety between dezocine injection and morphine injection for persistence of pain in Chinese cancer patients: a meta-analysis. Biosci Rep. 2017;37 (3):BSR20170243. doi:10.1042/BSR20170243

17. Childers WE, Abou-Gharbia MA. "I'll Be Back": the resurrection of dezocine. ACS Med Chem Lett. 2021;12(6):961-968. doi:10.1021/ acsmedchemlett.1c00233

18. Zhao X, Liu J, Ge S, et al. Saikosaponin A inhibits breast cancer by regulating Th1/Th2 balance. Front Pharmacol. 2019;10:624. doi:10.3389/fphar.2019.00624

19. Zhang W, Pan Y, Gou P, et al. Effect of xanthohumol on Th1/Th2 balance in a breast cancer mouse model. Oncol Rep. 2018;39 (1):280-288. doi:10.3892/or.2017.6094

20. Yao ZY, Jia Z, Xie YH, et al. Analgesic effect of dezocine in different doses on elderly patients undergoing abdominal operation under general anesthesia and its influence on stress response to postoperative tracheal extubation. Eur Rev Med Pharmacol Sci. 2017;21 (22):5223-5229. doi:10.26355/eurrev_201711_13845

21. Nair MP, Schwartz SA, Polasani R, et al. Immunoregulatory effects of morphine on human lymphocytes. Clin Diagn Lab Immunol. 1997;4(2):127-132. doi:10.1128/cdli.4.2.127-132.1997
22. Roy S, Balasubramanian S, Sumandeep S, et al. Morphine directs T cells toward T(H2) differentiation. Surgery. 2001;130(2):304-309. doi:10.1067/msy.2001.116033

23. Mao M, Qian Y, Sun J. Morphine suppresses T helper lymphocyte differentiation to Th1 type through PI3K/AKT pathway. Inflammation. 2016;39(2):813-821. doi:10.1007/s10753-016-0310-X

24. Gao M, Sun J, Jin W, Qian Y. Morphine, but not ketamine, decreases the ratio of Th1/Th2 in CD4-positive cells through T-bet and GATA3. Inflammation. 2012;35(3):1069-1077. doi:10.1007/s10753-011-9413-6

25. Messmer D, Hatsukari I, Hitosugi N, et al. Morphine reciprocally regulates IL-10 and IL-12 production by monocyte-derived human dendritic cells and enhances T cell activation. Mol Med. 2006;12(1112):284-290

26. Thomson IR, Harding G, Hudson RJ. A comparison of fentanyl and sufentanil in patients undergoing coronary artery bypass graft surgery. J Cardiothorac Vasc Anesth. 2000;14(6):652-656. doi:10.1053/jcan.2000.18307

27. Lee HM, Kil HK, Koo BN, et al. Comparison of sufentanil- and fentanyl-based intravenous patient-controlled analgesia on postoperative nausea and vomiting after laparoscopic nephrectomy: a prospective, double-blind, randomized-controlled trial. Int $\mathrm{J}$ Med Sci. 2020;17(2):207-213. doi:10.7150/ijms.39374

28. Peng Y, Yang J, Guo D, et al. Sufentanil postoperative analgesia reduce the increase of $\mathrm{T}$ helper 17 (Th17) cells and FoxP3 ${ }^{+}$regulatory $\mathrm{T}$ (Treg) cells in rat hepatocellular carcinoma surgical model: a randomised animal study. BMC Anesthesiol. 2020;20(1):212. doi:10.1186/s12871-020-01129-0

29. Gong L, Qin Q, Zhou L, et al. Effects of fentanyl anesthesia and sufentanil anesthesia on regulatory T cells frequencies. Int J Clin Exp Pathol. 2014;7(11):7708-7716.

30. Jagtap SV. Evaluation of CD4+ T-cells and CD8+ T-cells in triple-negative invasive breast cancer. Indian J Pathol Microbiol. 2018;61(4):477-478. doi:10.4103/IJPM.IJPM_201_18

31. Solis-Castillo LA, Garcia-Romo GS, Diaz-Rodriguez A, et al. Tumor-infiltrating regulatory $\mathrm{T}$ cells, CD8/Treg ratio, and cancer stem cells are correlated with lymph node metastasis in patients with early breast cancer. Breast Cancer. 2020;27(5):837-849. doi:10.1007/s12282-020-01079-y

32. Wang YH, Chai JR, Xu XJ, et al. Pharmacological characterization of dezocine, a potent analgesic acting as a $\kappa$ partial agonist and $\mu$ partial agonist. Sci Rep. 2018;8(1):14087. doi:10.1038/s41598-01832568-y

33. Mao XF, Ahsan MZ, Apryani E, et al. Dual $\mu$-opioid receptor and norepinephrine reuptake mechanisms contribute to dezocine- and tapentadol-induced mechanical antiallodynia in cancer pain. Eur J Pharmacol. 2020;876:173062. doi:10.1016/j.ejphar.2020.173062

34. Feng C, Feng M, Jiao R, et al. Effect of Dezocine on IL-12 and IL-10 secretion and lymphocyte activation by culturing dendritic cells from human umbilical cord blood. Eur J Pharmacol. 2017;796:110-114. doi:10.1016/j.ejphar.2016.12.035

35. Song Q, Liu G, Liu D, et al. Dezocine promotes T lymphocyte activation and inhibits tumor metastasis after surgery in a mouse model. Invest New Drugs. 2020;38(5):1342-1349. doi:10.1007/ s10637-020-00921-6

36. Ye Z, Zhang M, Ding N, et al. Antinociceptive effects of dezocine on complete Freund's adjuvant-induced inflammatory pain in rats. Exp Ther Med. 2018;15(6):5469-5474. doi:10.3892/etm.2018.6110

37. Wang F, Zhang X, Wang H, et al. Effects of dezocine and sufentanyl for postoperative analgesia on activity of NK, CD4+ and CD8+ cells in patients with breast cancer. Oncol Lett. 2019;17(3):3392-3398. doi:10.3892/ol.2019.9964

38. Wu L, Dong YP, Sun L, et al. Low concentration of dezocine in combination with morphine enhance the postoperative analgesia for thoracotomy. J Cardiothorac Vasc Anesth. 2015;29(4):950-954. doi:10.1053/j.jvca.2014.08.012 
39. Morgan D, Cook CD, Smith MA, et al. An examination of the interactions between the antinociceptive effects of morphine and various mu-opioids: the role of intrinsic efficacy and stimulus intensity. Anesth Analg. 1999;88(2):407-413. doi:10.1097/ 00000539-199902000-00035

40. Li NN, Huang YQ, Huang LE, et al. Dezocine antagonizes morphine analgesia upon simultaneous administration in rodent models of acute nociception. Pain Physician. 2017;20(3):E401-E409.

41. Zhang L, Xu J, Wang G, et al. [Consensus of clinical analgesic experts on dizocine]. Chin J Anesthesiol. 2020;40(6):641-664. Chinese.

42. Raigon-Ponferrada A, Recio MED, Guerrero-Orriach JL, et al. Breast Cancer and Anesthesia. Curr Pharm Des. 2019;25(28):2998-3004. doi: $10.2174 / 1381612825666190712183436$

43. Karcioglu O, Topacoglu H, Dikme O, et al. A systematic review of the pain scales in adults: which to use? Am J Emerg Med. 2018;36 (4):707-714. doi:10.1016/j.ajem.2018.01.008

44. Rostaing L, Tkaczuk J, Durand M, et al. Kinetics of intracytoplasmic Th1 and Th2 cytokine production assessed by flow cytometry following in vitro activation of peripheral blood mononuclear cells. Cytometry. 1999;35(4):318-328. doi:10.1002/(sici)1097-0320(19990401)35:4<318::aid-cyto4>3.0.co;2-4

45. Maino VC, Suni MA, Ruitenberg JJ. Rapid flow cytometric method for measuring lymphocyte subset activation. Cytometry. 1995;20 (2):127-133. doi:10.1002/cyto.990200205

46. Yang W, Chen X, Hu H. $\mathrm{CD}^{+}$T-Cell Differentiation In Vitro. Methods Mol Biol. 2020;2111:91-99. doi:10.1007/978-1-07160266-9_8

47. Ye W, Zhang X, Sun X. [Effects of on the expression of CD4 molecules on the surface of Th cells cultured in vitro]. J Immunol. 2018;21(2):104-106. Chinese.

48. Boland JW, Pockley AG. Influence of opioids on immune function in patients with cancer pain: from bench to bedside. Br J Pharmacol. 2018;175(14):2726-2736. doi:10.1111/bph.13903

49. Börner C, Lanciotti S, Koch T, Höllt V, Kraus J. $\mu$ opioid receptor agonist-selective regulation of interleukin-4 in $\mathrm{T}$ lymphocytes. $J$ Neuroimmunol. 2013;263(1-2):35-42. doi:10.1016/j.jneuroim.20 13.07.012
50. Eisenstein TK. The role of opioid receptors in immune system function. Front Immunol. 2019;10:2904. doi:10.3389/ fimmu.2019.02904

51. Stowell RD, Sipe GO, Dawes RP, et al. Noradrenergic signaling in the wakeful state inhibits microglial surveillance and synaptic plasticity in the mouse visual cortex [published correction appears in Nat Neurosci. 2020 Jan;23(1):152]. Nat Neurosci. 2019;22 (11):1782-1792. doi:10.1038/s41593-019-0514-0

52. Franchi S, Panerai AE, Sacerdote P. Buprenorphine ameliorates the effect of surgery on hypothalamus-pituitary-adrenal axis, natural killer cell activity and metastatic colonization in rats in comparison with morphine or fentanyl treatment. Brain Behav Immun. 2007;21 (6):767-774. doi:10.1016/j.bbi.2007.01.001

53. Sacerdote P, Bianchi M, Gaspani L, et al. The effects of tramadol and morphine on immune responses and pain after surgery in cancer patients. Anesth Analg. 2000;90(6):1411-1414. doi:10.1097/ 00000539-200006000-00028

54. Sacerdote P, Bianchi M, Gaspani L, et al. Effects of tramadol and its enantiomers on Concanavalin-A induced-proliferation and NK activity of mouse splenocytes: involvement of serotonin. Int J Immunopharmacol. 1999;21(11):727-734. doi:10.1016/s01920561(99)00048-X

55. Martino M, Rocchi G, Escelsior A, Fornaro M. Immunomodulation mechanism of antidepressants: interactions between serotonin/norepinephrine balance and Th1/Th2 balance. Curr Neuropharmacol. 2012;10(2):97-123. doi:10.2174/157015912800604542

56. Russo MA, Fiore NT, van Vreden C, et al. Expansion and activation of distinct central memory $\mathrm{T}$ lymphocyte subsets in complex regional pain syndrome [published correction appears in J Neuroinflammation. 2019 Apr 3;16(1):70]. J Neuroinflammation. 2019;16(1):63. doi:10.1186/s12974-019-1449-9

57. Machelska H, Celik MÖ. Opioid receptors in immune and glial cells-implications for pain control. Front Immunol. 2020;11:300. doi:10.3389/fimmu.2020.00300

\section{Publish your work in this journal}

Drug Design, Development and Therapy is an international, peerreviewed open-access journal that spans the spectrum of drug design and development through to clinical applications. Clinical outcomes, patient safety, and programs for the development and effective, safe, and sustained use of medicines are a feature of the journal, which has also been accepted for indexing on PubMed Central. The manuscript management system is completely online and includes a very quick and fair peer-review system, which is all easy to use. Visit http://www. dovepress.com/testimonials.php to read real quotes from published authors. 